Portuguese Journal of Political Science | Revista Portuguesa de Ciência Política ISSN: 1647-4090 | ISSN-e: 2184-2078 | 2020, Número 14, Páginas 47-58

DOI: $10.33167 / 2184-2078 . R P C P 2020.14 / p p .47-58$

\title{
Amazônia Brasileira na Pandemia: A Difícil Missão de Sobreviver ao Coronavírus e à Crise Política do País
}

\author{
Bárbara Beatriz Lobato Cruz ${ }^{*}$ \\ * Universidade do Minho, Portugal; barbaracrz08@gmail.com
}

\section{Resumo}

Este artigo tem como objetivo principal discutir o impacto da pandemia do Coronavírus na Amazônia brasileira, os seus desdobramentos e conflitos não só na floresta, mas também no povo habitante da região, sobretudo a situação dos povos indígenas e como a COVID-19 vem impactando as tribos de forma direta e indiretamente, através de exposição de opiniões, factos e contexto histórico, fatores de suma importância que ajudam a montar o panorama atual da Amazônia dentro da pandemia. Além disso, o presente artigo visa realizar uma análise da crise política que o Brasil enfrenta no momento e como esta influencia nos impactos sofridos pela macrorregião amazônica, a fim de evidenciar a necessidade de discussão - agora mais do que nunca - , de proteção e preservação da diversidade amazônica frente a um governo que se omite das responsabilidades para com a prevenção da identidade amazônica. A preocupação com a floresta amazônica não é algo recente, contudo, o momento atual é decisivo na história da maior floresta tropical do mundo.

Palavras-chave: Amazônia, Crise Política; Pandemia; Política Anti-indígena; Povos Indígenas 


\begin{abstract}
This article has as main objective to discuss the impact of the Coronavirus pandemic on the Brazilian Amazon, its consequences and conflicts not only in the forest but also in the people living in the region, especially the situation of indigenous peoples and how COVID-19 has been impacting the tribes directly and indirectly, through the exposure of opinions, facts and historical context, factors of paramount importance that help to build the current panorama of the Amazon within the pandemic. In addition, this article aims to analyse the political crisis that Brazil is facing at the moment and how it influences the impacts suffered by the Amazon macro-region, in order to highlight the need for discussion - now more than ever - , to protect and preserve Amazonian diversity in the face of a government that omits responsibility for the prevention of Amazonian identity. The concern with the Amazon rainforest is not something recent, however the current moment is decisive in the history of the largest tropical forest in the world.
\end{abstract}

Keywords: Amazon; Anti-indigenous Policy; Indigenous Peoples Pandemic; Political Crisis

\title{
1. Introdução
}

A perseguição aos indígenas da região amazônica brasileira infelizmente não é nenhuma novidade. Explorados desde 1500, assassinados e perseguidos, passam-se os séculos mas o índio brasileiro ainda continua lutando pelo reconhecimento de seus direitos básicos. A região Amazônica é frágil, está longe dos grandes centros urbanos do país e só é vista nos noticiários se algo que ocorrer na região impactar de alguma forma o Sudeste, região mais industrializada do país.

Deste modo, quando um acontecimento como a pandemia do Coronavírus de proporções globais ocorre, a preocupação com a Amazônia, seu povo e suas realidades redobra. Como proteger uma região a qual quem deveria defendê-la se omite dessa responsabilidade e toma medidas que visam a destruição da biodiversidade e genocídio dos diversos povos indígenas que habitam essa área há séculos? Um questionamento difícil de encontrar uma resposta, por isso devemos entender a conjuntura atual, analisar e procurar entender as formas que a pandemia afeta uma região de suma importância para o equilíbrio ambiental global.

Desde que a Organização Mundial da Saúde (OMS) reconheceu a pandemia do Coronavírus, em 11 de março de 2020, aos poucos o desmatamento e destruição da Amazônia foram desaparecendo dos noticiários. Com os olhos do mundo voltados para os desdobramentos da pandemia, os problemas enfrentados na região da floresta foram deixados em segundo plano, tal situação foi recebida com alegria entre os criminosos que invadem, destroem e desmatam a floresta, pois agora podiam agir de forma mais livre, uma vez que a imprensa tinha uma pandemia para se preocupar. 
Ainda não se sabe como a Amazônia será impactada pela crise do Coronavírus. A região possui uma dinâmica própria, por isso, vai levar um tempo para contabilizar todos os efeitos da pandemia na área, o que se pode fazer é analisar o que vem ocorrendo agora, fazer projeções e estimativas do futuro baseadas nos dados que temos agora, como a redução da fiscalização ambiental e o aumento do desemprego local. A pandemia acentuou os problemas sociais do Brasil, na região amazônica não seria diferente, por isso, este artigo tem como objetivo analisar os efeitos da crise do Coronavírus na Macrorregião Amazônica em meio à crise política brasileira.

\section{A relação do indígena brasileiro com a sua própria identidade brasileira}

A ideia de que o índio é um ser selvagem e, por isso, deve ser domado e civilizado é uma falácia que surgiu ainda em 1500, quando os europeus iniciaram a exploração das colônias americanas através da escravização dos povos nativos, e persiste até os dias atuais, se adequando a cada momento da história brasileira, sem nunca deixar de existir. A chegada dos europeus marcou o início de um crime silencioso que ainda resiste até os dias de hoje: o genocídio do povo indígena.

Estima-se que até a chegada dos portugueses em solo brasileiro, havia aproximadamente 5 milhões de índios vivendo no país, divididos em diversas tribos, como Tupinambá, Caraíba, Tupi-Guarani, entre outros. Contudo, a chegada dos colonizadores trouxe consigo conflitos armados, escravização e doenças antes desconhecidas pelos povos indígenas. Tais fatores foram decisivos para o extermínio de várias tribos.

Com o passar do tempo, tal situação apenas se agrava. Durante a ditadura chamada "Estado Novo" (1937-1945), o governo promoveu a "Marcha para o Oeste", a qual tinha como objetivo principal a ocupação e incorporação de áreas do centro-oeste brasileiro. Nesse sentido, algumas tribos isoladas nessa área foram encontradas e pacificadas. É nessa área que se encontra atualmente o Parque Indígena do Xingu, criado em 1961, considerado um marco na luta pela proteção dos povos nativos brasileiros, mesmo nessa época ainda não havendo uma legislação que garantisse de fato os direitos territoriais dos povos indígenas.

Já na década de 70, durante a ditadura militar no Brasil, houve uma forte campanha governamental para povoar a região amazônica. Lemas como "Integrar para não Entregar” faziam parte do Programa de Integração Nacional (PIN), o qual tinha como principal objetivo utilizar mão de obra nordestina para ocupar os "vazios demográficos” da região Norte do Brasil. Além disso, a construção da estrada batizada de Transamazônica, também foi utilizada como forma de ocupar a região amazônica, vista pelo governo militar como uma área cheia de riquezas que não podiam cair em mãos erradas. Ainda em 1973, o governo aprova o Estatuto do índio.

Em 1988 é promulgada a nova Constituição Federal do Brasil, que inovou ao finalmente versar sobre o direito originário dos índios:

Art. 231. São reconhecidos aos índios sua organização social, costumes, línguas, crenças e tradições, e os direitos originários sobre as terras que tra- 
dicionalmente ocupam, competindo à União demarcá-las, proteger e fazer respeitar todos os seus bens.

$\$ 1 .^{\circ}$ São terras tradicionalmente ocupadas pelos índios as por eles habitadas em caráter permanente, as utilizadas para suas atividades produtivas, as imprescindíveis à preservação dos recursos ambientais necessários a seu bem-estar e as necessárias a sua reprodução física e cultural, segundo seus usos, costumes e tradições.

$\$ 2 .^{\circ}$ As terras tradicionalmente ocupadas pelos índios destinam-se a sua posse permanente, cabendo-lhes o usufruto exclusivo das riquezas do solo, dos rios e dos lagos nelas existentes.

$\$ 3 .^{\circ} \mathrm{O}$ aproveitamento dos recursos hídricos, incluídos os potenciais energéticos, a pesquisa e a lavra das riquezas minerais em terras indígenas só podem ser efetivados com autorização do Congresso Nacional, ouvidas as comunidades afetadas, ficando-lhes assegurada participação nos resultados da lavra, na forma da lei.

$\$ 4 .^{\circ}$ As terras de que trata este artigo são inalienáveis e indisponíveis, e os direitos sobre elas, imprescritíveis.

$\$ 5 .^{\circ}$ É vedada a remoção dos grupos indígenas de suas terras, salvo, ad referendum do Congresso Nacional, em caso de catástrofe ou epidemia que ponha em risco sua população, ou no interesse da soberania do País, após deliberação do Congresso Nacional, garantido, em qualquer hipótese, o retorno imediato logo que cesse o risco.

$\$ 6^{\circ}$ São nulos e extintos, não produzindo efeitos jurídicos, os atos que tenham por objeto a ocupação, o domínio e a posse das terras a que se refere este artigo, ou a exploração das riquezas naturais do solo, dos rios e dos lagos nelas existentes, ressalvado relevante interesse público da União, segundo o que dispuser lei complementar, não gerando a nulidade e a extinção direito a indenização ou a ações contra a União, salvo, na forma da lei, quanto às benfeitorias derivadas da ocupação de boa-fé.

$\$ 7 .^{\circ}$ Não se aplica às terras indígenas o disposto no art. $174, \S \S 3 .^{\circ}$ e $4 .^{\circ}$. (Brasil, 1988)

Nesse sentido, é possível perceber que, na teoria, o indígena brasileiro está amparado pela legislação do país e possui direitos a serem resguardados, mesmo sendo um cenário diferente na prática.

\subsection{A diversidade e multiculturalidade amazônica}

É fato que, desde a colonização portuguesa até os dias atuais, a Amazônia é vista muito mais como um produto rentável às grandes metrópoles brasileiras do que é para a própria região da qual faz parte. De provedora de escravos indígenas, passando pela exploração da borracha pelo mercado internacional, até os dias atuais em que queima para dar lugar ao agronegócio, a Amazônia ainda é vista como um produto, ignorando a sua vasta riqueza natural e cultural. A história da região tem sido, da chegada dos primeiros europeus à Amazônia até os dias atuais, uma trajetória de perdas e danos. E nela, a Amazônia tem sido, e isso paradoxalmente, vítima daquilo 
que ela tem de mais especial - sua magia, sua exuberância e sua riqueza (Loureiro, 2002).

Para entender a Amazônia é necessário entender de forma ampla a região na qual está inserida, e, também, deixar de lado alguns mitos que foram criados, como por exemplo a ideia de que a floresta é resistente, auto recuperável e inesgotável, ou a imagem de que a fauna ser preservada é algum tipo de primitivismo e subdesenvolvimento, o qual precisa ser substituído por alguma atividade considerada produtiva. $\mathrm{O}$ modo econômico imposto à região ignora as realidades e ecossistemas que compõem a região amazônica. A Amazônia brasileira está espalhada por 9 Estados brasileiros (Amazonas, Acre, Roraima, Rondônia, Amapá, Pará, Maranhão, Tocantins e Mato Grosso), ocupando 61\% do território brasileiro. Dessa forma, é absurdo pensar que a floresta é hegemônica a esse ponto.

Com a justificativa de que se deve levar à região amazônica o desenvolvimento, as políticas públicas acabam por destruir a maior riqueza da floresta, sua biodiversidade. Nesse sentido, as políticas públicas voltadas para essa região estimulam a exploração da natureza, sem se preocupar com estudos mais aprofundados sobre os impactos ambientais que seriam causados por essas atividades econômicas. Como exemplifica Violeta Refkalefsky Loureiro:

Atividades econômicas tão diversas como a pecuária, a exploração madeireira, a mineração, a garimpagem e outras, que apresentam diferentes impactos sobre a natureza, vêm sendo desenvolvidas indiferentemente sobre áreas de florestas densas, nascentes e margens de rios, regiões de manguezais, nas planícies em encostas, em solos frágeis ou nos raros solos bem estruturados. E a maior parte dessas atividades tem produzido enorme e injustificável desperdício de recursos naturais.

Tal realidade é alarmante, uma vez que os crimes ambientais vêm crescendo na Amazônia. O desmatamento para extração de madeira ilegal ou para expansão de agropecuária, os conflitos entre garimpeiros ilegais e indígenas pela exploração de áreas de preservação, são alguns dos problemas mais latentes na região, a qual recebe amparo do poder público cada vez menor. Além disso, órgãos como o Instituto Brasileiro do Meio Ambiente e dos Recursos Naturais Renováveis (IBAMA) e do Instituto Chico Mendes de Conservação da Biodiversidade (ICMBio), vêm sofrendo com o corte de verbas por parte do governo brasileiro, dificultando a manutenção de operações contra a destruição da Amazônia.

\section{A chegada do Coronavírus no Brasil e seus efeitos no Norte do país}

A pandemia do Coronavírus teve início no Brasil no dia 26 de fevereiro de 2020, quando o primeiro caso foi confirmado no país. Desde então, vem atravessando uma batalha contra um inimigo silencioso que já fez mais de 100 mil vítimas fatais. Nesse sentido, é importante lembrar que o Brasil é um país de dimensões continentais, com 5 regiões de realidades diferentes, dessa forma já era esperado que o vírus atingisse uma velocidade diferente em cada região, contudo, a falta de medidas governamen- 
tais prévias para o controle da circulação do vírus, aliada à crise política e econômica que o país atravessa, foram pontos chaves para os resultados catastróficos que ocorreram e ainda estão acontecendo. Além disso, é importante ressaltar que durante a pandemia o cargo de ministro da saúde foi trocado 2 vezes e, até o momento em que esse artigo foi escrito, quem comanda a pasta ainda é um ministro interino desde 15 de maio de 2020.

A região Norte do país foi uma das primeiras a ser afetada e a ter seu sistema de saúde colapsado. O estado do Amazonas foi o mais afetado, seguido pelo Pará. Os meses de abril, maio e junho foram os que concentraram o maior número de internações por Coronavírus nesses estados. Vale ressaltar que a região Norte é a mais desprovida de médicos, respiradores e leitos de UTI (Mendonça, Rocha, Pinheiro \& Oliveira, 2020). No momento atual, a pandemia é considerada já mais controlada nos centros urbanos nortistas, entretanto o que preocupa agora é o avanço do vírus para o interior, atingindo comunidades ribeirinhas, quilombolas e indígenas.

Considerados pela Organização Mundial da Saúde (OMS) como um dos povos mais vulneráveis ao Coronavírus, os indígenas das américas são mais expostos à pobreza, desnutrição, desemprego e doenças transmissíveis. Em julho de 2020, a Organização Pan-Americana de Saúde (OPAS), escritório regional da OMS, emitiu sua preocupação com os indígenas americanos, sobretudo os que vivem na região da Amazônia brasileira. De acordo com a diretora da OPAS, Clarissa Etienne, os índios brasileiros que habitam na bacia amazônica possuem taxa de incidência do vírus 5 vezes maior que a taxa do país.

Tal realidade não é apenas uma infeliz coincidência. $\mathrm{O}$ governo brasileiro vem já há algum tempo dificultando o acesso dos índios a seus direitos básicos. Em 8 de julho de 2020, o presidente Jair Bolsonaro sancionou com vetos a lei que previa proteção dos povos indígenas durante a pandemia. Dentre os trechos vetados pelo presidente estão: a obrigação do governo de fornecer aos povos indígenas acesso à água potável e distribuição de materiais de higiene e desinfecção nas aldeias, obrigatoriedade de liberação de verbas de emergência por parte da União destinadas à saúde indígena, ações governamentais para garantir o acesso a leitos hospitalares pelos povos indígenas e quilombolas, e obrigação do governo em facilitar o acesso dos índios ao auxilio emergencial.

Ademais, o grupo que mais sofre ao entrar em contato com o coronavírus são os idosos, dessa forma, os mais atingidos nas aldeias são os anciãos, índios idosos que carregam consigo a sabedoria do seu povo e seus rituais tradicionais. Nesse sentido, muitos líderes indígenas adoecem e não resistem ao vírus, o que ocorre aqui é o risco de muitas tradições indígenas se perderem para sempre, pois os idosos estão morrendo sem que consigam ensinar às futuras gerações os costumes do seu próprio povo, fomentando a perda da identidade cultural daquela tribo. Até o mês de setembro de 2020, momento que este artigo foi escrito, o Brasil possuía um total de 30.218 casos de COVID-19 entre os povos indígenas e 789 óbitos de índios. Tais números são disponibilizados pela Articulação do Povos Indígenas do Brasil (Apib). 
Infelizmente, o cenário atual não mostra razões para sermos otimistas. Os povos indígenas estão sendo duramente atacados desde antes da chegada do coronavírus, seja pelo confronto com madeireiros que derrubam e queimam a floresta, ou garimpos ilegais que invadem as terras indígenas e contaminam os rios. Agora um inimigo invisível ataca e o Governo Federal pouco faz para tentar evitar uma tragédia, não há estratégia de contenção com o objetivo de frear os estragos causados pela pandemia, e tal realidade é alarmante. A verdade é que os vírus, principalmente os que atacam o sistema respiratório, sempre foram vetores de vários danos para os povos nativos brasileiros, sendo utilizado até mesmo como mecanismo de dominação e colonização pelos europeus. Séculos se passaram, mas pouco mudou a respeito.

\section{A política governamental anti-indígena e seus efeitos na floresta Amazônica}

Atualmente no Brasil, o interesse econômico pela terra vem sendo fundamental para que uma política anti-indígena venha ganhando força. Agentes públicos e privados não escondem mais seus interesses pela ocupação econômica dessas áreas e implementam ações ofensivas contra esses povos, como por exemplo, se opor à devida demarcação de terras e proteção dos direitos básicos desses povos nativos. Como especificam Maria Augusta Assirati e Luís Gustavo Guerreiro Moreira:

Os desdobramentos objetivos da ofensiva ruralista criaram uma atmosfera tão desfavorável ao avanço da implementação dos direitos dos indígenas, que trouxeram desafios até então não enfrentados, já que pela primeira vez desde a redemocratização - setores dos três poderes do Estado passaram a se manifestar de forma inequívoca em favor da revisão do arcabouço normativo, que estabelece direitos e garantias a essas populações.

O Brasil tem como um de seus grandes problemas históricos a questão do latifúndio, terras extensas concentradas nas mãos de alguns fazendeiros e latifundiários, sendo uma de suas questões mais latentes a reforma agrária, por isso, o país está entre os 10 países do mundo com maior desigualdade na repartição da propriedade rural. Contudo, para que ocorresse uma reforma agrária de forma justa, seria necessário respeitar a diversidade cultural das regiões brasileiras, as políticas de preservação e conservação de áreas protegidas, como territórios indígenas, quilombolas e unidades de conservação. Tais parâmetros dificultam a realização desse projeto, uma vez que há uma bancada ruralista influente no Congresso Nacional que não possui pretensão alguma de dividir suas terras em prol do meio ambiente.

A Frente Parlamentar da Agropecuária (FPA) - também conhecida como bancada ruralista - é composta por 200 deputados e aproximadamente 20 senadores, representantes dos interesses de produtores rurais e latifundiários e costumam votar em bloco quando o projeto de lei é de seu interesse, principalmente quando o foco é a questão indígena. Como podemos perceber segundo os dados abaixo: 


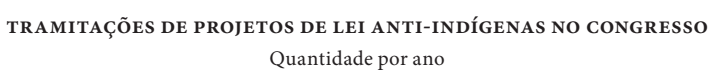

Quantidade por ano

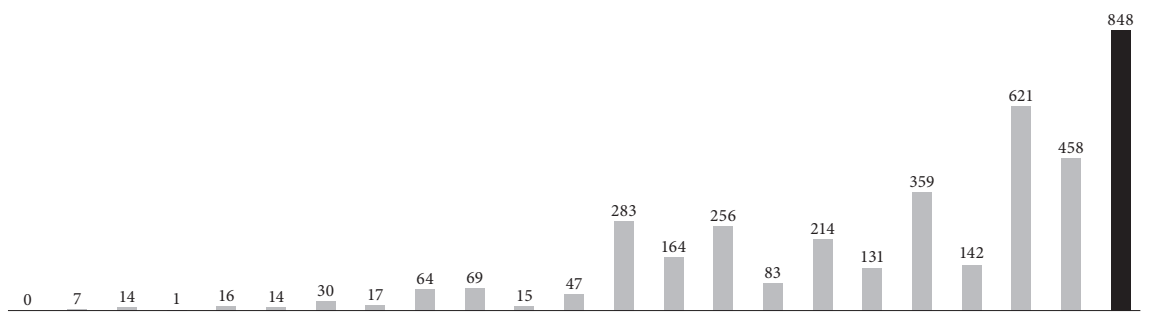

$\begin{array}{lllllllllllllllllllllll}1995 & 1996 & 1997 & 1998 & 1999 & 2000 & 2001 & 2002 & 2003 & 2004 & 2005 & 2006 & 2007 & 2008 & 2009 & 2010 & 2011 & 2012 & 2013 & 2014 & 2015 & 2016 & 2017\end{array}$

Figura 1. Aumento de projetos de lei anti-indígena no legislativo brasileiro

Fonte: Câmara dos Deputados, Cimi, Funai.

Como podemos perceber pela Figura 1, o número desse tipo de projeto de lei vem crescendo nos últimos anos e com o governo atual a realidade tende a piorar. Podemos afirmar que a atual formação do Congresso Nacional brasileiro é a mais conservadora desde 1964, pois há um aumento de fazendeiros, religiosos e policiais eleitos por partidos de direita, formando o que conhecemos como "bancada BBB": boi, bíblia e bala. Foram esses políticos que apoiaram e participam do atual governo. Eleito em 2018, Jair Bolsonaro não esconde que governa para esses parlamentares, deixando claro que, pessoalmente, não possui interesse nenhum na proteção da Amazônia e de seus povos.

\subsection{Os resultados da má atuação do Governo Federal frente aos desdobramentos da pandemia na Amazônia}

Nesse sentido, o que acontece é uma grande omissão do Estado brasileiro perante as questões ambientais, sobretudo agora em tempos de pandemia. Desde a campanha eleitoral, Bolsonaro fala abertamente em defesa da atividade garimpeira na Amazônia. Nesse momento em que as atenções do mundo estão voltadas para a COVID-19, o governo brasileiro vem se omitindo do dever de combater atividade de garimpo ilegal em terras indígenas, tal omissão nada mais é que o resultado de uma política anti-indígena de um governo genocida.

Prova desse terrível cenário é a gravação da reunião ministerial de 22 de abril de 2020, divulgado a mando do Supremo Tribunal Federal Brasileiro (STF), na qual o ministro do Meio Ambiente, Ricardo Salles, diz que o período da pandemia seria ideal para aprovação de reformas de "simplificação" e "desregulamentação" das leis ambientais. Salles defende justamente que tais medidas sejam tomadas durante a crise do coronavírus pois a imprensa estaria ocupada tratando da pandemia e não daria a devida atenção para as medidas que seriam tomadas contra o meio ambiente 
e os povos indígenas. Nas palavras de Salles, o atual momento era o ideal para, nas palavras dele, "ir passando a boiada, ir mudando todo regulamento", o que ele quis dizer com essa linguagem coloquial era que já era a hora de facilitar a aprovação de tais reformas propostas.

O mais alarmante é que mesmo com a repercussão dessa reunião, Salles já conseguiu alguns de seus objetivos. Entre os meses de março e abril ocorreu uma série de alterações normativas no Instituto Brasileiro do Meio Ambiente e dos Recursos Naturais Renováveis (IBAMA), como por exemplo, a autorização de regularização de propriedades rurais em terras indígenas, permitindo a invasão e exploração de terras indígenas ainda não homologadas, a diminuição da distância entre áreas povoadas e aquelas que ocorrem utilização de agrotóxicos, tal prática é proibida em vários países europeus há uma década, pois é responsável pela contaminação de moradores locais como indígenas e quilombolas. Além disso, também foi assinada uma portaria que restringe o acesso de servidores do IBAMA à imprensa, tal decisão foi duramente criticada uma vez que expõe mais uma vez a conivência do governo com a censura.

As pretensões de Salles não param por ai, contudo, com a pressão feita por movimentos sociais e ONGs que lançaram campanhas contra o pronunciamento do ministro do Meio Ambiente, algumas medidas retrocederam, como por exemplo a "PL da grilagem", projeto de lei patrocinado pela FPA, o qual promove a regularização de terras públicas ilegalmente ocupadas. Ademais, mesmo com a repercussão negativa das falas de Salles, o presidente Bolsonaro transferiu do Ministério do Meio Ambiente para o Ministério da Agricultura a competência para realizar concessões de florestas públicas em âmbito federal.

Em 2019 o desmatamento na Amazônia atingiu o maior patamar em 10 anos e ao que tudo indica, os índices de 2020 também serão alarmantes. A postura do Governo Federal é o mais preocupante, se passa a ideia de que tudo está permitido, sobrepondo a economia à realidade amazônica.

\section{Conclusão}

Portanto, podemos perceber que a pandemia do coronavírus está impactando a região Amazônica de forma direta e indiretamente. Seja pela ação do vírus, fazendo vítimas fatais nos centros urbanos amazônicos, mas também no interior, onde o acesso a atendimento médico é muito difícil e em alguns casos nulo, ou pela destruição da floresta através de atividades ilegais de criminosos que se aproveitam do momento atual para porem em prática seus diversos crimes ambientais em prol do lucro. A região amazônica pede socorro, mas essa ajuda não parece que vai chegar.

Os fatos nos mostram que a floresta amazônica é mais uma vítima do imperialismo atual, que visa o crescimento econômico dos que estão no topo, deixando a pobreza e miséria para quem está embaixo nessa escala global de desenvolvimento. Além disso, os grandes centros urbanos tentam impor um ritmo de desenvolvimento para a região amazônica que não funciona no local, pois não respeita a diversidade da área, as diferentes realidades, a multiculturalidade e os diversos problemas en- 
frentados pelo povo que integra a grande Amazônia. Não é uma mera coincidência que a região Norte do país seja uma das mais carentes do Brasil, por muito tempo se tem a ideia errada de que o Norte é apenas mato, floresta e índio - tudo isso visto de forma pejorativa, a região vai muito além de riquezas minerais, exploradas por multinacionais gigantes, há também a riqueza de seu povo, ignorado pelo resto do país.

A pandemia do coronavírus escancarou a carência que o povo da Amazônia brasileira enfrenta no que diz respeito ao acesso a direitos básicos como saúde pública de qualidade. O colapso da rede pública nessa região evidencia o descaso de décadas por parte do Governo Federal, o qual pouco fez para preservar a vida nas aldeias. À medida que uma onda de conservadorismo toma o país é levantado um sentimento patriota e nacionalista - principalmente entre os que ainda apoiam o presidente Jair Bolsonaro, tal sentimento teria como objetivo principal exaltar o Brasil e o orgulho de ser brasileiro, entretanto percebe-se que esses indivíduos não possuem nenhuma simpatia pelas causas indígenas, muito pelo contrário, defendem a ocupação da Amazônia para fins econômicos. Esse cenário é um bom exemplo da síndrome de inferioridade do brasileiro médio, o qual acredita que tem mais em comum com um europeu do que com um índio pertencente à sua própria nação.

Sendo assim, concluímos que a batalha contra todos as consequências geradas pela pandemia de 2020 na região amazônica está longe de ter acabado e, ao que tudo indica, esses efeitos continuarão a ser sentidos mesmo depois que o vírus for totalmente controlado, seja com uma vacina ou um tratamento mundialmente reconhecido. O que se vê é um governo genocida que insiste em atacar as políticas de proteção da floresta e dos povos indígenas. A COVID-19 ainda não parou de gerar vítimas fatais nos territórios indígenas e infelizmente essa será uma realidade que ainda vai durar. O estrago será muito maior uma vez que a pandemia se une à crise política instaurada no país por um governo despreparado que carrega a responsabilidade da crise ambiental, sanitária e humanitária que o Brasil enfrenta e que ainda não possui nenhuma perspectiva de melhora.

Data de receção: 09/09/2020

Data de aprovação: 17/11/2020

\section{Referências}

Brasil. Constituição (1988). Constituição da República Federativa do Brasil. Brasília, DF: Senado Federal: Centro Gráfico, 1988.

Cunha, C. (2015). O Indígena no Brasil - Uma Luta Histórica para Existir. Disponível em: $<$ https://vestibular.uol.com.br/resumo-das-disciplinas/atualidades/o-indigena-nobrasil-uma-luta-historica-para-existir.htm>.

Wenzel, F. (2020). Pandemia terá Impacto direto no desmatamento da Amazônia. Eco. Disponível em: <https://www.oeco.org.br/reportagens/pandemia-tera-impacto-diretono-desmatamento-da-amazonia/>. 
Assirati, M. A. e Moreira, L. G. (2019). O Estado Anti-Indígena: Da Colônia Ao Novo Golpe. Tensões Mundiais, Fortaleza, v. 15, n. 29, p. 97-118, 2019.

UNICEF Brasil. (2020). Juventude indígena fala sobre o impacto da pandemia em suas comunidades. Disponível em: <https://www.unicef.org/brazil/historias/juventudeindigena-fala-sobre-o-impacto-da-pandemia-em-suas-comunidades\#: :text=A\%20 pandemia $\% 20$ do $\% 20$ novo $\% 20$ coronav $\%$ C3\%ADrus,passaram $\% 20 \mathrm{a} \% 20$ enfrentar\%20novos\%20desafios.\&text=Nos\%20depoimentos\%2C\%20fica\%20clara\%20 a,a\%20perda\%20de\%20seus\%20anci\%C3\%A3os>.

Loureiro, V. R. (2002). Amazônia: uma história de perdas e danos, um futuro a (re)construir. Estud. av. vol.16 no.45 São Paulo May/Aug. 2002. Disponível em: $<$ https://www.scielo. br/scielo.php?script=sci_arttext\&pid=S0103-40142002000200008>.

Oliveira, R. (2020). Abandono de povos indígenas na pandemia deixa dúvida se governo age por "omissão ou estratégia". Pública, agência de jornalismo investigativo. Disponível em: $<$ https://apublica.org/2020/08/abandono-de-povos-indigenas-na-pandemia-deixaduvida-se-governo-age-por-omissao-ou-estrategia/\#Link2>.

Mendonça, F. D., Rocha S. S., Pinheiro, D. P., Oliveira, S. V. (2020). Região Norte do Brasil e a pandemia de COVID-19: análise socioeconômica e epidemiológica. Journal Health NPEPS. 2020 janeiro-junho; 5(1):20-37.

Santos, G. V. (2020). Os povos indígenas em tempos de pandemia. Conselho Indigenista Missionário. Disponível em: <https://cimi.org.br/2020/06/povos-indigenas-tempospandemia/>.

Marcondes, D. Agência pública - Indígenas enfrentam a maior ofensiva parlamentar em 20 anos. Agência Envolverde Jornalismo, [online], 24 abr. 2018. Disponível em: <https:// envolverde.com.br/agencia-publica-indigenas-enfrentam-a-maior-ofensiva-parlamentar-em-20-anos/>.

Nicolav, V. (2020). O que passou na "boiada" de Ricardo Salles durante a pandemia?. Brasil de Fato. Disponível em: <https://www.brasildefato.com.br/2020/06/09/o-que-passouna-boiada-de-ricardo-salles-durante-a-pandemia $>$.

Dantas, C. (2020). Brasil tem 10,3 mil casos confirmados de coronavírus entre indígenas, dizem entidades. Portal G1. Disponível em: <https:/g1.globo.com/bemestar/coronavirus/ noticia/2020/07/02/brasil-tem-mais-de-103-mil-casos-confirmados-de-coronavirusentre-indigenas-dizem-entidades.ghtml>.

Modelli, L. (2020). Comunidades indígenas na bacia amazônica são cinco vezes mais atingidas pela Covid-19 que o resto do Brasil, alerta Opas. Portal G1. Disponível em: <https:// g1.globo.com/bemestar/coronavirus/noticia/2020/07/14/comunidades-indigenasna-bacia-amazonica-sao-cinco-vezes-mais-atingidas-pela-covid-19-que-o-resto-dobrasil-alerta-opas.ghtml>.

Yanomami, D. K. (2020). COVID-19 e os Povos Indígenas. Covid-19 Socioambiental. Disponível em: <https://covid19.socioambiental.org/>. 


\section{Sobre o autor}

bárbara beatriz lobato cruz Mestranda em Ciências Políticas pela Escola de Economia e Gestão da Universidade do Minho. Bacharel em Direito formada pelo Centro Universitário do Estado do Pará (Brasil), além de possuir capacitação em Negociações Internacionais pela Universidade de São Paulo. Atualmente, colunista trimestral na revista online Relações Exteriores (Brasil). Durante a graduação em direito fez parte do grupo de estudos Poder e Democracia. Possui artigos apresentados em eventos nacionais. Trabalho voluntário com jovens em situação de risco voltado à educação política. Principais áreas de investigação: cooperação internacional pelo meio ambiente; Mercosul; direito internacional; proteção da mulher refugiada; política interna brasileira; história contemporânea da política Latino-americana. [https://orcid.org/0000-0002-3539-2767]

\section{About the author}

BÁrbara beAtriz lobato Cruz Master's degree in Political Science from the School of Economics and Management of the University of Minho. Bachelor's degree in Law from the University Center of the State of Pará (Brazil), besides having training in International Negotiations from the University of São Paulo. Currently, is a quarterly columnist in the online magazine Foreign Relations (Brazil). During the law degree, she was part of the Power and Democracy study group. She has articles presented at national events. Volunteer work with at-risk young people focused on political education. Main areas of research: international cooperation for the environment; Mercosul; international law; protection of refugee women; Brazilian internal policy; contemporary history of Latin American politics.

[https://orcid.org/0000-0002-3539-2767] 